\title{
Magnesium and Osteoporosis: Current State of Knowledge and Future Research Directions
}

\author{
Sara Castiglioni ${ }^{1}$, Alessandra Cazzaniga ${ }^{1}$, Walter Albisetti ${ }^{2}$ and Jeanette A. M. Maier ${ }^{1, *}$ \\ 1 Department of Biomedical and Clinical Sciences L. Sacco, University of Milan, Via GB Grassi 74, \\ Milan I-20157, Italy; E-Mails: sara.castiglioni@unimi.it (S.C.); alessandra.cazzaniga@unimi.it (A.C.) \\ 2 Department of Biomedical, Surgical and Dental Sciences, University of Milan, Via Commenda 10, \\ Milan I-20157, Italy; E-Mail: walter.albisetti@unimi.it \\ * Author to whom correspondence should be addressed; E-Mail: jeanette.maier@unimi.it; \\ Tel.: +39-02-5031-9648; Fax: +39-02-5031-9659.
}

Received: 18 June 2013; in revised form: 14 July 2013 / Accepted: 22 July 2013 /

Published: 31 July 2013

\begin{abstract}
A tight control of magnesium homeostasis seems to be crucial for bone health. On the basis of experimental and epidemiological studies, both low and high magnesium have harmful effects on the bones. Magnesium deficiency contributes to osteoporosis directly by acting on crystal formation and on bone cells and indirectly by impacting on the secretion and the activity of parathyroid hormone and by promoting low grade inflammation. Less is known about the mechanisms responsible for the mineralization defects observed when magnesium is elevated. Overall, controlling and maintaining magnesium homeostasis represents a helpful intervention to maintain bone integrity.
\end{abstract}

Keywords: osteoporosis; magnesium; osteoblast; osteoclast

\section{Introduction}

Osteoporosis is a multifactorial disease characterized by loss of bone mass due to a marked bone microarchitecture deterioration [1]. Physiologically, bone is constantly remodeled by concerted and coordinated interactions between osteoclasts, the cells primarily involved in bone resorption, and osteoblasts, which ensure bone formation and mineralization. Osteoporosis results from an imbalance between bone deposition and resorption. The consequent decline of bone mass increases the risk of 
fractures, in particular hip and spine fractures, which are associated with substantial pain and suffering, disability, and even death [1].

Osteoporosis affects millions people worldwide, predominantly postmenopausal women. In the United States low bone mass is a threat for more than 40 million people [2]. In Europe, the prevalence of osteoporosis is expected to affect more than 30 million people by the year 2050 [3]. Frequently associated with aging, osteoporosis is a major health concern since the aging population will double over the next decade with enormous cost burden on the healthcare systems. Osteoporosis therapies are available and fall into two classes, anabolic drugs, which induce bone formation, and anti-resorptive drugs, which retard bone resorption. In addition, modifications of lifestyle, i.e., regular physical activity, no alcohol, no smoke, balanced diet, are highly recommended in patients with osteoporosis [1]. In general, because osteoporosis reflects peak bone mass determined by factors preceding skeletal maturity [4], there is a growing interest in preventive strategies for decreasing the incidence of osteoporosis in future decades. Dietary interventions are among them. Indeed, nutritional factors are of particular importance to bone health and they are modifiable by providing food-based recommendations. A correct diet is particularly important in the young, before skeletal maturity is reached. While calcium and vitamin $\mathrm{D}$ have been the master focus of nutritional prevention of osteoporosis, several additional food constituents - such as phytoestrogens, flavonoids, vitamins A, B, $\mathrm{C}, \mathrm{E}$, folate - and minerals among which copper, zinc, selenium, iron fluoride and magnesium (Mg), are known to be important [5]. In particular, a significant association has been found between bone density and the intake of $\mathrm{Mg}$, an essential micronutrient with a wide range of metabolic, structural and regulatory functions [6].

\section{Magnesium and the Bone: Molecular, Biochemical and Cellular Insights}

About $60 \%$ of total $\mathrm{Mg}$ is stored in the bone. One third of skeletal $\mathrm{Mg}$ resides on cortical bone either on the surface of hydroxyapatite or in the hydration shell around the crystal [7]. It serves as a reservoir of exchangeable $\mathrm{Mg}$ useful to maintain physiological extracellular concentrations of the cation [6]. Bone surface $\mathrm{Mg}$ levels are related to serum $\mathrm{Mg}$. Accordingly, surface bone $\mathrm{Mg}$ increases with Mg loading, as described in chronic renal disease [8]. The larger fraction of bone $\mathrm{Mg}$ is probably deposited as an integral part of the apatite crystal and its release follows the resorption of bone. Apart from a structural role in the crystals, $\mathrm{Mg}$ is essential to all living cells, including osteoblasts and osteoclasts. Intracellularly, $\mathrm{Mg}$ is vital for numerous physiological functions. First of all, $\mathrm{Mg}$ is fundamental for ATP, the main source of energy in the cells. Moreover, $\mathrm{Mg}$ is cofactor of hundreds of enzymes involved in lipid, protein and nucleic acid synthesis. Because of its positive charge, $\mathrm{Mg}$ stabilizes cell membranes. It also antagonizes calcium [9] and functions as a signal transducer [10]. It is therefore not surprising that alterations of $\mathrm{Mg}$ homeostasis impact on cell and tissue functions.

\section{Low Magnesium and Osteoporosis: Experimental Evidence}

In several studies on different species, dietary $\mathrm{Mg}$ restriction promotes osteoporosis [11]. Bones of $\mathrm{Mg}$ deficient animals are brittle and fragile, microfractures of the trabeculae can be detected and mechanical properties are severely impaired [12]. Consequently, it is not surprising that a $\mathrm{Mg}$ deficient 
diet has a negative effect on the peri-implant cortical bone markedly decreasing tibial cortical thickness [13].

Several direct and indirect mechanisms contribute to the effects of low $\mathrm{Mg}$ on bone density (Figure 1). Mg deficiency rapidly leads to hypomagnesemia, which is in part buffered through the mobilization of surface $\mathrm{Mg}$ from the bone. In addition, the newly formed crystals of apatite are larger and better structured in $\mathrm{Mg}$ deficient animals than controls, and this affects bone stiffness [14]. It should also be recalled that low Mg intake retards cartilage and bone differentiation as well as matrix calcification [15]. In experimental $\mathrm{Mg}$ deficiency in rodents, decreased bone formation is partly due to reduced osteoblastic activity [16]. Accordingly, the number of osteoblasts detected by histomorphometry is reduced [17,18] and the levels of two markers of osteoblastic function, namely alkaline phosphatase and osteocalcin, are decreased [14]. Moreover, an increase in the number of osteoclasts has been described [11]. It is noteworthy that these results in vivo have been confirmed by in vitro studies and some molecular pathways involved have been unraveled. Indeed, low extracellular $\mathrm{Mg}$ inhibits osteoblast growth by increasing the release of nitric oxide through the upregulation of inducible nitric oxide synthase [19], while it increases the number of osteoclasts generated from bone marrow precursors [20].

Figure 1. Present knowledge about the mechanisms involved in linking Mg deficiency and osteoporosis. Remarkably, similar events are implicated in experimental models and in humans. Because the vasculature plays an important role in bone remodeling, we also hypothesize that low $\mathrm{Mg}$ induced-endothelial dysfunction contributes to the decline of bone mass.

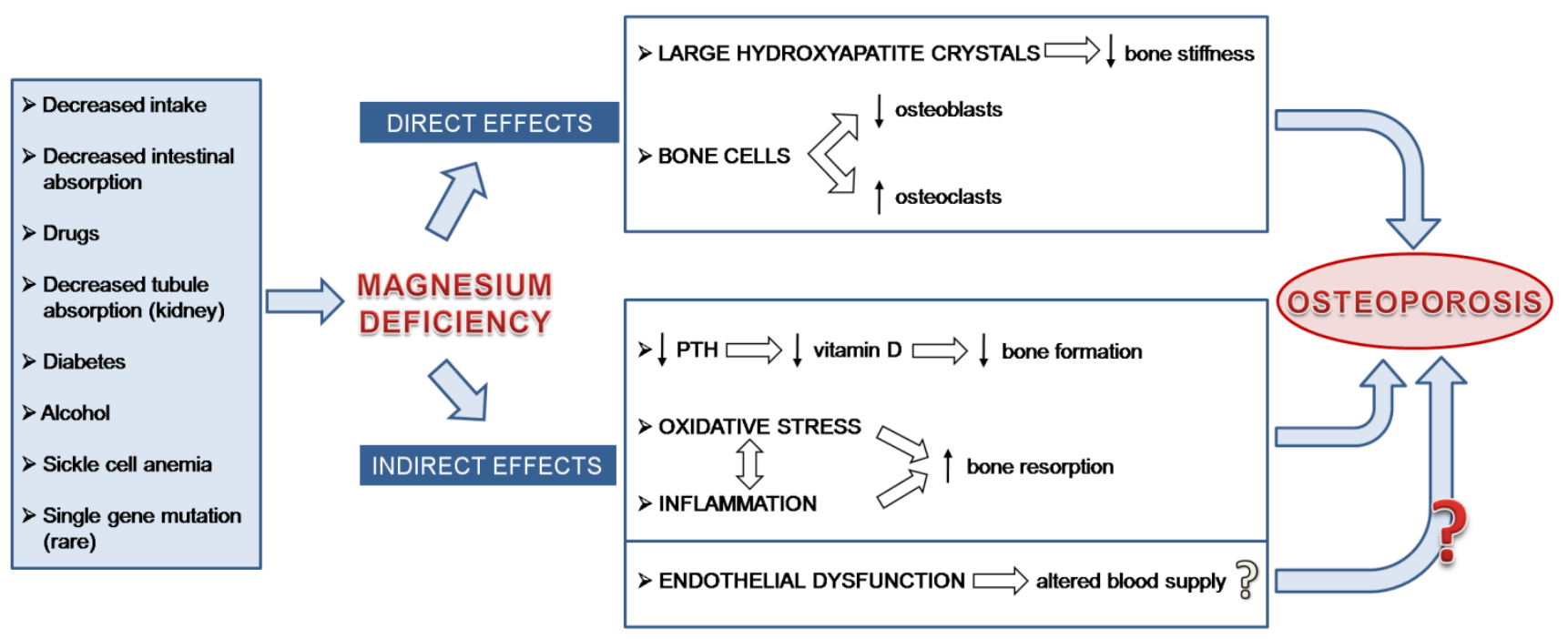

Apart from direct effects on the structure and the cells of the skeleton, $\mathrm{Mg}$ deficiency impacts on the bone also indirectly by affecting the homeostasis of the two master regulators of calcium homeostasis, i.e., parathyroid hormone $(\mathrm{PTH})$ and $1,25(\mathrm{OH})_{2}$-vitamin $\mathrm{D}$ thus leading to hypocalcemia. In most species, hypomagnesemia impairs secretion of PTH and renders target organs refractory to PTH. Because PTH signaling implies the increase of cyclic AMP through the activation of adenylate cyclase, which requires $\mathrm{Mg}$ as a cofactor, resistance to PTH might be due, in part, to the decreased activity of this enzyme [21]. Reduced secretion of PTH or impaired peripheral response to the hormone lead to 
low serum concentrations of $1,25(\mathrm{OH})_{2}$-vitamin $\mathrm{D}[11,18]$. To this purpose it is noteworthy that 25-hydroxycholecalciferol-1-hydroxylase requires $\mathrm{Mg}$ [22] and consequently $\mathrm{Mg}$ deficiency reduces the activity of the enzyme.

Hypomagnesemia also promotes inflammation [23] and a relation exists between inflammation and bone loss [24]. In Mg deficient rodents, TNF $\alpha$, IL-1s and IL-6 are increased both in serum and in the bone marrow microenvironment [23]. These cytokines not only amplify osteoclast while inhibiting osteoblast function but also perpetuate inflammation. Besides, substance $\mathrm{P}$ is released at high levels in $\mathrm{Mg}$ deficiency [18]. In addition to enhancing pro-inflammatory cytokine secretion, substance $\mathrm{P}$ released on nerve ending in bone stimulates the activity of the osteoclasts [18].

It is also relevant that $\mathrm{Mg}$ restriction promotes oxidative stress, partly as a consequence of inflammation partly because of the reduced anti-oxidant defenses which occur upon $\mathrm{Mg}$ restriction [25]. The increased amounts of free radicals potentiate the activity of osteoclasts and depress that of osteoblasts [26].

A last issue that is overlooked in experimental models is about the vasculature in the bone of $\mathrm{Mg}$ deficient animals. An adequate blood supply is necessary for bone health. Interestingly, decreased intraosseous blood vessel volume and number seems to be relevant in the development of post-nerve-injury osteoporosis [27] and in old-age associated osteoporosis [28]. Overall, all experimental data from animal studies indicate that reduced dietary intake of $\mathrm{Mg}$ is a risk factor for osteoporosis through a constellation of different mechanisms.

\section{Low Magnesium and Osteoporosis: Studies in Humans}

Nutritional monitoring programs have shown an inadequate dietary Mg intake in Europe and North America [29] which leads to subclinical Mg deficiency. This is mainly due to the features of the western diet, rich in processed foods and relatively poor in micronutrients. How can $\mathrm{Mg}$ intake be optimized? Since the center of chlorophyll contains $\mathrm{Mg}$, green vegetables are excellent sources of the metal. Also, nuts, seeds, unprocessed grains and some legumes contain large amounts of $\mathrm{Mg}$. However, diet is not the only determinant. For a long time, the existence of differences in $\mathrm{Mg}$ handling on a genetic basis has been suspected. Only recently some light has been shed on this issue. In the last decade, rare cases of hypomagnesemia have been linked to hereditary single-gene mutations [30] (Table 1). These uncommon disorders lead to the identification and characterization of some molecular players in Mg homeostasis. These findings fostered studies on the genome and, by single nucleotide polymorphisms, six different genomic regions were individuated that contain variants reproducibly associated with low serum Mg levels [31]. Interestingly, only one of the loci described, namely TRPM6, had a known role in influencing Mg concentrations in humans [32]. These results open new perspectives in our understanding of the complex mechanisms involved in regulating $\mathrm{Mg}$ absorption and distribution and should be taken into account when the outcomes of interventional studies are evaluated. 
Table 1. Inherited disorders leading to hypomagnesemia. The function of the wild type protein is briefly described.

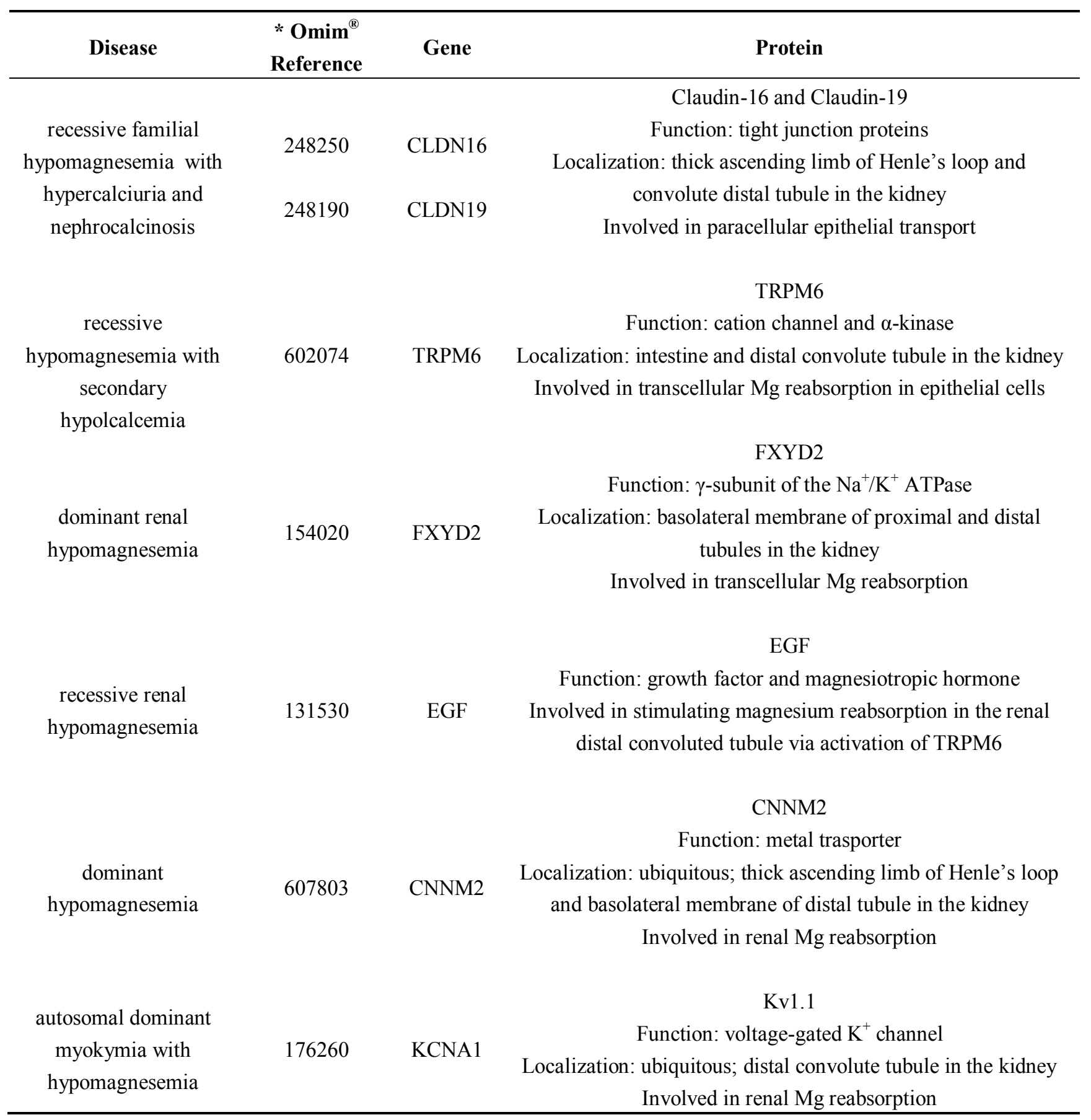

* Omim: Online Mendelian Inheritance in Man.

Because $\mathrm{Mg}$ homeostasis is regulated through a complex network of transporters in the intestine and in the kidney, it is not surprising that $\mathrm{Mg}$ deficiency is associated with chronic gastrointestinal and renal diseases [32]. It also complicates diabetes mellitus, sickle cell anemia, therapies with some classes of diuretics, antibiotics or anti-neoplastic drugs [33,34]. In addition, it is very common in the elderly and in alcoholists. Some of these conditions share elevated C-reactive protein, a marker of systemic inflammation, as a common denominator and an inverse correlation exists between $\mathrm{Mg}$ intake and C-reactive protein [35]. 
Also in humans $\mathrm{Mg}$ deficiency contributes to osteoporosis. Low serum $\mathrm{Mg}$ is a co-contributing factor to osteopenia in adults with sickle cell anemia [36]. Moreover, an association between serum $\mathrm{Mg}$ and bone density has been reported in pre and post menopausal women [4,37]. Mg intake was positively associated with bone mass density in surviving members of the Framingham study [38]. The same result was obtained in white but not in black males and females (age 70-79), thereby raising the possibility of racial differences in $\mathrm{Mg}$ handling [39] which might be explained in the light of the aforementioned genetic variants of genes implicated in $\mathrm{Mg}$ homeostasis [31]. In agreement with the aforementioned results, $\mathrm{Mg}$ supplementation is beneficial in osteoporotic women [40,41].

Building healthy bone throughout life is a strategy to prevent osteoporosis. To this purpose it is interesting to note that pre-adolescent dietary intake of $\mathrm{Mg}$ positively relates to bone mass density in young adulthood as detected by quantitative ultrasound determination of the calcaneus [42] and that $\mathrm{Mg}$ supplementation for 12 months has a positive effect on the accrual of bone mass in the hip of peripuberal Caucasian girls [43]. Mg supplementation is therefore important in the periadolescent group, given the suboptimal dietary $\mathrm{Mg}$ intake documented in food surveys in western countries. It is also interesting that $\mathrm{Mg}$ intake is an independent predictor of bone density in young elite swimmers [44].

The mechanisms explaining the effects of $\mathrm{Mg}$ deficiency on the bone in humans are similar to what has been described in experimental models:

(i) low Mg can directly affect the bone by altering the structure of apatite crystals and by acting on bone cells. Indeed, osteoporotic women with demonstrated $\mathrm{Mg}$ deficiency have larger and better organized crystals in trabecular bone than controls, while in women undergoing hormone replacement therapy bone $\mathrm{Mg}$ is increased and associates with low cristallinity index [45]. We here recall that when crystals are large bones do not bear a normal load.

(ii) $\mathrm{Mg}$ deficiency associates with the reduction of the levels of PTH, the induction of end-organ resistance to PTH and the decrease of vitamin D [11,46]. Interestingly, many osteoporotic post-menopausal women who are vitamin D deficient and have low PTH levels are also Mg deficient and $\mathrm{Mg}$ supplementation corrects these biochemical abnormalities [47]. Moreover hypomagnesemic diabetic children normalize their levels of $1,25(\mathrm{OH})_{2}$-vitamin D upon supplementation with $\mathrm{Mg}$ [48].

(iii) $\mathrm{Mg}$ deficiency associates with low grade inflammation [4,34] and, as mentioned above, inflammatory cytokines stimulate bone remodelling and osteopenia [23].

(iv) $\mathrm{Mg}$ deficiency promotes endothelial dysfunction [49] and it is known that endothelial health is important for bone health [50]. On these bases, it is tempting to speculate about the possibility that osteoporosis might be considered a vascular disease of the bone.

(v) Another aspect to consider is the evidence that adults on a western diet develop a low-grade acidosis which is intensified by aging. Recently, the acid load imposed by this diet has been suggested to play a role in the pathophysiology of osteoporosis. Indeed, metabolic acidosis has been shown to lead to calcium loss from bone, to inhibit osteoblast function and stimulate osteoclast activity, and to impair bone mineralization [51]. Accordingly, a neutralizing diet improves bone micro-architecture and bone mineral density [52]. It is therefore feasible that part of the effects of $\mathrm{Mg}$ on the skeleton is due to its capability to act as a buffer for the acid produced by the typical western diet [53].

In spite of the evidence showing that $\mathrm{Mg}$ is beneficial for the skeleton, warning results were reported in the Women's Health Initiative Study where it is shown that postmenopausal women with the highest quintile of $\mathrm{Mg}$ intake have the highest incidence of wrist fracture [5]. These results are in 
keeping with some data showing that elevated $\mathrm{Mg}$ might have harmful effects on osseous metabolism and parathyroid gland function, leading to mineralization defects. Indeed, high bone $\mathrm{Mg}$ inhibits the formation of hydroxyapatite crystals by competing with calcium and by binding to pyrophosphate forming an insoluble salt, not degraded by the enzymes [54]. These events contribute also to osteomalacic renal osteodystrophy and adynamic bone disease [54]. In patients with chronic renal failure or in individuals undergoing dialysis, serum $\mathrm{Mg}$ concentrations are frequently elevated and correlate with mineralization defects [54]. Additional intriguing studies were performed on premature infants with osteopenia secondary to $\mathrm{MgSO}_{4}$ maternal administration for preterm labor [55,56]. Since $\mathrm{Mg}$ is a calcium antagonist [9], it is feasible to propose that high concentrations of $\mathrm{Mg}$ alter calcium $/ \mathrm{Mg}$ ratio, thus leading to dysregulated cell functions. Accordingly, an in vitro inhibitory effect of high $\mathrm{Mg}$ on osteoblast differentiation and mineralizing activity has been shown [57].

Overall, an optimal range of $\mathrm{Mg}$ concentrations might be required to ensure bone homeostasis. More studies are required in vitro and in vivo about the effects of high $\mathrm{Mg}$ concentrations on bone metabolism and structure not only to provide correct nutritional guidelines but also because of the use of $\mathrm{Mg}$ as an orthopedic implant material.

\section{Critical Issues and Future Perspective}

$\mathrm{Mg}$ has been defined the forgotten electrolyte. Indeed, while a lot of literature is available on calcium, not as much is known about $\mathrm{Mg}$ in biomedicine and, specifically, in bone homeostasis. In addition, the measurement of serum $\mathrm{Mg}$ is seldom requested in spite of the evidence that hypomagnesemia is very common in industrialized countries. Because $\mathrm{Mg}$ (i) interferes with calciotropic hormones and (ii) has been proposed as a natural calcium antagonist, an evaluation of $\mathrm{Mg} /$ calcium balance seems to be pivotal in general, and in particular in the case of bone physiology and pathology. To our knowledge, there is only one study showing that the ratio of serum and hair calcium to $\mathrm{Mg}$ is a significant indicator of bone mass density [58]. Recent advancement in our knowledge of bone physiology has shown the complexity of the network of molecules involved in maintaining skeletal health. The canonical Wnt pathway is emerging as fundamental for the maintenance of bone homeostasis [59]. Briefly, Wnts are essential in determining the fate of mesenchymal precursors and in regulating osteoblast proliferation, apoptosis, differentiation and function [59]. Accordingly, Wnt antagonist sclerostin is involved in osteoporosis and inflammatory bone loss [60]. No data are available at the moment on this pathway in Mg deficiency. Another hot area of research relates to the use of mesenchymal stem cells (MSC) for regenerative medicine in different fields including orthopaedic surgery. To our knowledge nothing is known about the effects of different concentrations of Mg on MSC survival, growth and differentiation both in vivo and in vitro, apart from the studies performed with MSC on biodegradable Mg alloys [61]. Also osteocytes have not been studied in relation to $\mathrm{Mg}$. Far from being passive by-standers in the bone, the osteocytes are emerging as mechanotransducers and orchestrators of bone remodelling [62]. Many other challenging questions about $\mathrm{Mg}$ and the bone are still unanswered. 


\section{Conclusions}

Although the evidence is still fragmentary, most of the experimental and clinical data available in the literature point to $\mathrm{Mg}$ as a contributor factor to bone health. Consequently, optimizing $\mathrm{Mg}$ intake might represent an effective and low-cost preventive measure against osteoporosis in individuals with documented $\mathrm{Mg}$ deficiency, while doubts remain about supplementing the general population with the mineral since too much $\mathrm{Mg}$ seems to have detrimental effects on the bone [5,57].

\section{Conflict of Interest}

The authors declare no conflict of interest.

\section{References}

1. Rachner, T.D.; Khosla, S.; Hofbauer, L.C. Osteoporosis: Now and the future. Lancet 2011, 377, 1276-1287.

2. Nieves, J.W. Osteoporosis: The role of micronutrients. Am. J. Clin. Nutr. 2005, 81, 1232S-1239S.

3. Ström, O.; Borgström, F.; Kanis, J.A.; Compston, J.; Cooper, C.; McCloskey, E.V.; Jönsson, B. Osteoporosis: Burden, health care provision and opportunities in the EU: A report prepared in collaboration with the International Osteoporosis Foundation (IOF) and the European Federation of Pharmaceutical Industry Associations (EFPIA). Arch. Osteoporos. 2011, 6, 59-155.

4. Song, Y.; Li, T.Y.; van Dam, R.M.; Manson, J.E.; Hu, F.B. Magnesium intake and plasma concentrations of markers of systemic inflammation and endothelial dysfunction in women. Am. J. Clin. Nutr. 2007, 85, 1068-1074.

5. Nieves, J.W. Skeletal effects of nutrients and nutraceuticals, beyond calcium and vitamin D. Osteoporos. Int. 2013, 24, 771-786.

6. Jahnen-Dechent, W.; Ketteler, M. Magnesium basics. Clin. Kidney J. 2012, 5, i3-i14.

7. Alfrey, A.C.; Miller, N.L. Bone magnesium pools in uremia. J. Clin. Investig. 1973, 52, 3019-3027.

8. Cunningham, J.; Rodriguez, M.; Messa, P. Magnesium in chronic kidney disease Stages 3 and 4 and in dialysis patients. Clin. Kidney J. 2012, 5, i39-i51.

9. Iseri, L.T.; French, J.H. Magnesium: Nature's physiologic calcium blocker. Am. Heart J. 1984, 108, 188-193.

10. Li, F.Y.; Chaigne-Delalande, B.; Kanellopoulou, C.; Davis, J.C.; Matthews, H.F.; Douek, D.C.; Cohen, J.I.; Uzel, G.; Su, H.C.; Lenardo, M.J. Second messenger role for $\mathrm{Mg}^{2+}$ revealed by human T-cell immunodeficiency. Nature 2011, 475, 471-476.

11. Rude, R.K.; Singer, F.R.; Gruber, H.E. Skeletal and hormonal effects of magnesium deficiency. J. Am. Coll. Nutr. 2009, 28, 131-141.

12. Boskey, A.L.; Rimnac, C.M.; Bansal, M.; Federman, M.; Lian, J.; Boyan, B.D. Effect of short-term hypomagnesemia on the chemical and mechanical properties of rat bone. J. Orthop. Res. 1992, 10, 774-783.

13. Belluci, M.M.; Giro, G.; del Barrio, R.A.; Pereira, R.M.; Marcantonio, E.; Orrico, S.R. Effects of magnesium intake deficiency on bone metabolism and bone tissue around osseointegrated implants. Clin. Oral Implants Res. 2011, 22, 716-721. 
14. Creedon, A.; Flynn, A.; Cashman, K. The effect of moderately and severely restricted dietary magnesium intakes on bone composition and bone metabolism in the rat. Br. J. Nutr. 1999, 82, $63-71$.

15. Schwartz, R.; Reddi, A.H. Influence of magnesium depletion on matrix-induced endochondral bone formation. Calcif. Tissue Int. 1979, 29, 15-20.

16. Rude, R.K.; Gruber, H.E. Magnesium deficiency and osteoporosis: Animal and human observations. J. Nutr. Biochem. 2004, 15, 710-716.

17. Rude, R.K.; Kirchen, M.E.; Gruber, H.E.; Meyer, M.H.; Luck, J.S.; Crawford, D.L. Magnesium deficiency-induced osteoporosis in the rat: Uncoupling of bone formation and bone resorption. Magnes. Res. 1999, 12, 257-267.

18. Rude, R.K.; Gruber, H.E.; Wie, L.Y.; Frausto, A.; Mills, B.G. Magnesium deficiency: Effect on bone and mineral metabolism in the mouse. Calcif. Tissue Int. 2003, 72, 32-41.

19. Leidi, M.; Dellera, F.; Mariotti, M.; Banfi, G.; Crapanzano, C.; Albisetti, W.; Maier, J.A. Nitric oxide mediates low magnesium inhibition of osteoblast-like cell proliferation. J. Nutr. Biochem. 2012, 23, 1224-1229.

20. Belluci, M.M.; Schoenmaker, T.; Rossa-Junior, C.; Orrico, S.R.; de Vries, T.J.; Everts, V. Magnesium deficiency results in an increased formation of osteoclasts. J. Nutr. Biochem. 2013, doi: 10.1016/j.jnutbio.2012.12.008.

21. Pironi, L.; Malucelli, E.; Guidetti, M.; Lanzoni, E.; Farruggia, G.; Pinna, A.D.; Barbiroli, D.; Iotti, S. The complex relationship between magnesium and serum parathyroid hormone: A study in patients with chronic intestinal failure. Magnes. Res. 2009, 22, 37-43.

22. Gray, R.W.; Omdahl, J.L.; Ghazarian, J.G.; DeLuca, H.F. 25-Hydroxycholecalciferol-1 hydroxylase. Subcellular location and properties. J. Biol. Chem. 1972, 247, 7528-7532.

23. Mazur, A.; Maier, J.A.; Rock, E.; Gueux, E.; Nowacki, W.; Rayssiguier, Y. Magnesium and the inflammatory response: Potential physiopathological implications. Arch. Biochem. Biophys. 2007, $458,48-56$.

24. Baker-LePain, J.C.; Nakamura, M.C.; Lane, N.E. Effects of inflammation on bone: An update. Curr. Opin. Rheumatol. 2011, 23, 389-395.

25. Wolf, F.I.; Trapani, V.; Simonacci, M.; Boninsegna, A.; Mazur, A.; Maier, J.A. Magnesium deficiency affects mammary epithelial cell proliferation: Involvement of oxidative stress. Nutr. Cancer 2009, 61, 131-136.

26. Garrett, I.R.; Boyce, B.F.; Oreffo, R.O.; Bonewald, L.; Poser, J.; Mundy, G.R. Oxygen-derived free radicals stimulate osteoclastic bone resorption in rodent bone in vitro and in vivo. J. Clin. Investig. 1990, 85, 632-639.

27. Ding, W.G.; Yan, W.H.; Wei, Z.X.; Liu, J.B. Difference in intraosseous blood vessel volume and number in osteoporotic model mice induced by spinal cord injury and sciatic nerve resection. J. Bone Miner. Metab. 2012, 30, 400-407.

28. Prisby, R.D.; Ramsey, M.W.; Behnke, B.J.; Dominguez, J.M.; Donato, A.J.; Allen, M.R.; Delp, M.D. Aging reduces skeletal blood flow, endothelium-dependent vasodilation, and NO bioavailability in rats. J. Bone Miner. Res. 2007, 22, 1280-1288.

29. Rosanoff, A.; Weaver, C.M.; Rude, R.K. Suboptimal magnesium status in the United States: Are the health consequences underestimated? Nutr. Rev. 2012, 70, 153-164. 
30. Naderi, A.S.; Reilly, R.F. Hereditary etiologies of hypomagnesemia. Nat. Clin. Pract. Nephrol. 2008, 4, 80-89.

31. Meyer, T.E.; Verwoert, G.C.; Hwang, S.J.; Glazer, N.L.; Smith, A.V.; van Rooij, F.J.; Ehret, G.B.; Boerwinkle, E.; Felix, J.F.; Leak, T.S.; et al. Genome-wide association studies of serum magnesium, potassium, and sodium concentrations identify six loci influencing serum magnesium levels. PLoS Genet. 2010, 6, doi: 10.1371/journal.pgen.1001045.

32. Runnels, L.W. TRPM6 and TRPM7: A Mul-TRP-PLIK-cation of channel functions. Curr. Pharm. Biotechnol. 2011, 12, 42-53.

33. Geiger, H.; Wanner, C. Magnesium in diseases. Clin. Kidney Dis. 2012, 5, i25-i38.

34. Rodriguez-Moran, M.; Simental Mendia, L.E.; Zambrano-Galvan, G.; Guerrero-Romero, F. The role of magnesium in type 2 diabetes: A brief clinical-based review. Magnes. Res. 2011, 24, $156-162$.

35. Chacko, S.A.; Song, Y.; Nathan, L.; Tinker, L.; de Boer, I.H.; Tylavsky, F.; Wallace, R.; Liu, S. Relations of dietary magnesium intake to biomarkers of inflammation and endothelial dysfunction in an ethnically diverse cohort of postmenopausal women. Diabetes Care 2010, 33, 304-310.

36. Elshal, M.F.; Bernawi, A.E.; Al-Ghamdy, M.A.; Jalal, J.A. The association of bone mineral density and parathyroid hormone with serum magnesium in adult patients with sickle-cell anaemia. Arch. Med. Sci. 2012, 8, 270-276.

37. Saito, N.; Tabata, N.; Saito, S.; Andou, Y.; Onaga, Y.; Iwamitsu, A.; Sakamoto, M.; Hori, T.; Sayama, H.; Kawakita, T. Bone mineral density, serum albumin and serum magnesium. J. Am. Coll. Nutr. 2004, 23, 701S-703S.

38. Tucker, K.L.; Hannan, M.T.; Chen, H.; Cupples, L.A.; Wilson, P.W.; Kiel, D.P. Potassium, magnesium, and fruit and vegetable intakes are associated with greater bone mineral density in elderly men and women. Am. J. Clin. Nutr. 1999, 69, 727-736.

39. Ryder, K.M.; Shorr, R.I.; Bush, A.J.; Kritchevsky, S.B.; Harris, T.; Stone, K.; Cauley, J.; Tylavsky, F.A. Magnesium intake from food and supplements is associated with bone mineral density in healthy older white subjects. J. Am. Geriatr. Soc. 2005, 53, 1875-1880.

40. Stendig-Lindberg, G.; Koeller, W.; Bauer, A.; Rob, P.M. Experimentally induced prolonged magnesium deficiency causes osteoporosis in the rat. Eur. J. Intern. Med. 2004, 15, 97-107.

41. Tranquilli, A.L.; Lucino, E.; Garzetti, G.G.; Romanini, C. Calcium, phosphorus and magnesium intakes correlate with bone mineral content in postmenopausal women. Gynecol. Endocrinol. 1994, 8, 55-58.

42. Wang, M.C.; Moore, E.C.; Crawford, P.B.; Hudes, M.; Sabry, Z.I.; Marcus, R.; Bachrach, L.K. Influence of pre-adolescent diet on quantitative ultrasound measurements of the calcaneus in young adult women. Osteoporos. Int. 1999, 9, 532-535.

43. Carpenter, T.O.; DeLucia, M.C.; Zhang, J.H.; Bejnerowicz, G.; Tartamella, L.; Dziura, J.; Petersen, K.F.; Befroy, D.; Cohen, D. A randomized controlled study of effects of dietary magnesium oxide supplementation on bone mineral content in healthy girls. J. Clin. Endocrinol. Metab. 2006, 91, 4866-4872.

44. Matias, C.N.; Santos, D.A.; Monteiro, C.P.; Vasco, A.M.; Baptista, F.; Sardinha, L.B.; Laires, M.J.; Silva, A.M. Magnesium intake mediates the association between bone mineral density and lean soft tissue in elite swimmers. Magnes. Res. 2012, 25, 120-125. 
45. Cohen, L.; Kitzes, R. Infrared spectroscopy and magnesium content of bone mineral in osteoporotic women. Isr. J. Med. Sci. 1981, 17, 1123-1125.

46. Rude, R.K.; Adams, J.S.; Ryzen, E.; Endres, D.B.; Niimi, H.; Horst, R.L.; Haddad, J.G.; Singer, F.R. Low serum concentrations of 1,25-dihydroxyvitamin D in human magnesium deficiency. J. Clin. Endocrinol. Metab. 1985, 61, 933-940.

47. Sahota, O.; Mundey, M.K.; San, P.; Godber, I.M.; Hosking, D.J. Vitamin D insufficiency and the blunted PTH response in established osteoporosis: The role of magnesium deficiency. Osteoporos. Int. 2006, 17, 1013-1021.

48. Saggese, G.; Federico, G.; Bertelloni, S.; Baroncelli, G.I.; Calisti, L. Hypomagnesemia and the parathyroid hormone-vitamin D endocrine system in children with insulin-dependent diabetes mellitus: Effects of Mg administration. J. Pediatr. 1991, 118, 220-225.

49. Maier, J.A. Endothelial cells and magnesium: Implications in atherosclerosis. Clin. Sci. (Lond.) 2012, 122, 397-407.

50. Warburton, D.E.; Nicol, C.W.; Gatto, S.N.; Bredin, S.S. Cardiovascular disease and osteoporosis: Balancing risk management. Vasc. Health Risk Manag. 2007, 3, 673-689.

51. Arnett, T.R. Extracellular pH regulates bone cell function. J. Nutr. 2008, 138, 415S-418S.

52. Jehle, S.; Hulter, H.N.; Krapf, R. Effect of potassium citrate on bone density, microarchitecture, and fracture risk in healthy older adults without osteoporosis: A randomized controlled trial. J. Clin. Endocrinol. Metab. 2013, 98, 207-217.

53. Weng, L.; Webster, T.J. Nanostructured magnesium has fewer detrimental effects on osteoblast function. Int. J. Nanomed. 2013, 8, 1773-1781.

54. Navarro-González, J.F.; Mora-Fernández, C.; García-Pérez, J. Clinical implications of disordered magnesium homeostasis in chronic renal failure and dialysis. Semin. Dial. 2009, 22, 37-44.

55. Yokoyama, K.; Takahashi, N.; Yada, Y.; Yasunori, K.; Kawamata, R.; Uehara, R.; Kono, Y.; Honma, Y.; Momoi, M.Y. Prolonged maternal magnesium administration and bone metabolism in neonates. Early Hum. Dev. 2010, 86, 187-191.

56. Kaplan, W.; Haymond, M.W.; Karaviti, L.P. Osteopenic effects of MgSO4 in multiple pregnancies. J. Pediatr. Endocrinol. Metab. 2006, 19, 1225-1230.

57. Leidi, M.; Dellera, F.; Mariotti, M.; Maier, J.A. High magnesium inhibits human osteoblast differentiation in vitro. Magnes. Res. 2011, 24, 1-6.

58. Song, C.H.; Barrett-Connor, E.; Chung, J.H.; Kim, S.H.; Kim, K.S. Associations of calcium and magnesium in serum and hair with bone mineral density in premenopausal women. Biol. Trace Elem. Res. 2007, 118, 1-9.

59. Clevers, H. Wnt/beta-catenin signaling in development and disease. Cell 2006, 127, 469-480.

60. Albisetti, W.; Giarratana, L.S.; Viganò, C.; Castiglioni, S.; Maier, J.A. Sclerostin: A novel player regulating bone mass in inflammation? Eur. J. Inflamm. 2013, in press.

61. Yang, C.; Yuan, G.; Zhang, J.; Tang, Z.; Zhang, X.; Dai, K. Effects of magnesium alloys extracts on adult human bone marrow-derived stromal cell viability and osteogenic differentiation. Biomed. Mater. 2010, 5, doi:10.1088/1748-6041/5/4/045005. 
62. Bonewald, L.F. The amazing osteocyte. J. Bone Miner. Res. 2011, 26, 229-238.

(C) 2013 by the authors; licensee MDPI, Basel, Switzerland. This article is an open access article distributed under the terms and conditions of the Creative Commons Attribution license (http://creativecommons.org/licenses/by/3.0/). 